\title{
Disease-related determinants are associated with mortality in dementia due to Alzheimer's disease
}

\author{
Hanneke F. M. Rhodius-Meester ${ }^{1 *}$, Hilkka Liedes ${ }^{2}$, Ted Koene ${ }^{3}$, Afina W. Lemstra', Charlotte E. Teunissen ${ }^{4}$,
} Frederik Barkhof ${ }^{5,6,7}$, Philip Scheltens ${ }^{1}$, Mark van Gils ${ }^{2}$, Jyrki Lötjönen ${ }^{2,8}$ and Wiesje M. van der Flier ${ }^{1,9}$

\begin{abstract}
Background: Survival after dementia diagnosis varies considerably. Previous studies were focused mainly on factors related to demographics and comorbidity rather than on Alzheimer's disease (AD)-related determinants. We set out to answer the question whether markers with proven diagnostic value also have prognostic value. We aimed to identify disease-related determinants associated with mortality in patients with AD.

Methods: We included 616 patients (50\% female; age $67 \pm 8$ years; mean Mini Mental State Examination score 22 \pm 3 ) with dementia due to AD from the Amsterdam Dementia Cohort. Information on mortality was obtained from the Dutch Municipal Register. We used age- and sex-adjusted Cox proportional hazards analysis to study associations of baseline demographics, comorbidity, neuropsychology, magnetic resonance imaging (MRI) (medial temporal lobe, global cortical and parietal atrophy, and measures of small vessel disease), and cerebrospinal fluid (CSF) ( $\beta$-amyloid 1-42, total tau, and tau phosphorylated at threonine 181 [p-tau]) with mortality (outcome). In addition, we built a multivariate model using forward selection.

Results: After an average of $4.9 \pm 2.0$ years, 213 (35\%) patients had died. Age- and sex-adjusted Cox models showed that older age (HR 1.29 [95\% Cl 1.12-1.48]), male sex (HR 1.60 [95\% Cl 1.22-2.11]), worse scores on cognitive functioning (HR 1.14 [95\% Cl 1.01-1.30] to 1.31 [95\% Cl 1.13-1.52]), and more global and hippocampal atrophy on MRI (HR 1.18 [95\% Cl 1.01-1.37] and HR 1.18 [95\% Cl 1.02-1.37]) were associated with increased risk of mortality. There were no associations with comorbidity, level of activities of daily living, apolipoprotein $E(A P O E) \varepsilon 4$ status, or duration of disease. Using forward selection, the multivariate model included a panel of age, sex, cognitive tests, atrophy of the medial temporal lobe, and CSF p-tau.

Conclusions: In this relatively young sample of patients with $A D$, disease-related determinants were associated with an increased risk of mortality, whereas neither comorbidity nor APOE genotype had any prognostic value.
\end{abstract}

Keywords: Alzheimer's disease, Prognosis, Mortality, Diagnostic test assessment

\section{Background}

Dementia due to Alzheimer's disease $(\mathrm{AD})$ is, by definition, a progressive disorder [1]. For patients, a diagnosis is not the endpoint, but rather the beginning of the subsequent trajectory of disease. Physicians are fairly good at establishing an accurate diagnosis, but they are hardly able

\footnotetext{
*Correspondence: h.rhodius@vumc.nl

${ }^{1}$ Alzheimer Center, Department of Neurology, VU University Medical Center, Amsterdam Neuroscience, P.O. Box 7057, 1007, MB, Amsterdam, The Netherlands

Full list of author information is available at the end of the article
}

to predict the course of the disease for the individual patient. In general, patients with dementia due to AD have a shorter life expectancy than the general population, with average survival being between 5 and 10 years [2-4]. Yet, survival time varies considerably between individuals.

Determinants of mortality in AD have been examined in various studies. Most have been focused on demographic factors or on clinical factors such as severity of cognitive impairment, dependency, and comorbidity [5-9]. Male sex and older age have been associated with increased risk of mortality in $\mathrm{AD}[2,3,10]$. Cardiovascular diseases and 
risk factors such as hypertension and diabetes mellitus have been identified as determinants of mortality, but only in studies of older patients with dementia [11-15]. Few studies have been focused on AD-specific factors, such as cerebrospinal fluid (CSF) and magnetic resonance imaging (MRI) markers. More severe neuronal degeneration, as reflected by a high total tau (tau) concentration and whole-brain atrophy, has been suggested as a determinant of mortality [12, 16-18]. In one study, microbleeds were associated with mortality in $\mathrm{AD}$, and white matter hyperintensities (WMH) were associated with mortality in allcause dementia [12].

Researchers in previous studies tended to evaluate only a few prognostic factors per study and included mainly patients aged 75 years and older, who are at risk of mortality owing to their advanced age even without a dementia diagnosis [3, 19]. Prognostic factors may be different for patients with early-onset AD, who are younger and have less comorbidity but are prone to a more aggressive disease course [10, 20-22]. We aimed to investigate the prognostic value of baseline clinical data, including demographics, comorbidity, neuropsychology, and CSF and MRI biomarkers, as determinants of mortality in dementia due to $\mathrm{AD}$.

\section{Methods}

\section{Patients}

In this longitudinal study, we included 616 patients with a baseline diagnosis of dementia due to AD from a memory clinic-based cohort (the Amsterdam Dementia Cohort) who had a baseline visit between 2000 and 2014 [23]. Subjects were selected if a neuropsychological test battery was available at baseline, with a baseline Mini Mental State Examination (MMSE) score $\geq 16$ and a minimum followup of 2 years. At baseline, patients received a standardized and multidisciplinary workup, including medical history; physical, neurological, and neuropsychological examinations; MRI; laboratory tests; and lumbar puncture for CSF measurements. Years of education and self-reported duration of complaints were recorded. For the assessment of activities of daily living, we used the Disability Assessment for Dementia (DAD) [24]. We included all data that were collected within 6 months of baseline diagnosis. Diagnoses were made in a multidisciplinary consensus meeting. Patients were diagnosed with probable $\mathrm{AD}$ using the criteria of the National Institute of Neurological and Communicative Disorders and Stroke/Alzheimer's Disease and Related Disorders Association; all patients also met the core clinical criteria of the National Institute on Aging-Alzheimer's Association for AD dementia $[25,26]$.

\section{Medical history}

We recorded and defined the presence (yes/no) of hypertension (history of hypertension and/or use of antihypertensive drugs), hypercholesterolemia (history of hypercholesterolemia and/or use of cholesterollowering drugs), diabetes (history of diabetes mellitus and/or use of antidiabetic drugs), and cardiovascular disease (at least one of the following: history of coronary heart disease, heart failure, heart disease, peripheral vascular disease, stroke, and/or transient ischemic attack). Furthermore, we dichotomized smoking status (never smoked versus current or history of smoking) and counted the medications used per patient.

\section{Neuropsychological tests}

Cognitive function was assessed at baseline with a standardized test battery in which the MMSE was used for global cognitive functioning [27]. For memory, the Visual Association Test (VAT) and the Rey Auditory Verbal Learning Task (RAVLT) were included [28, 29]. To measure mental speed and attention, we used Trail Making Test A (TMT-A) and the forward condition of the digit span. Trail Making Test B (TMT-B) and the backward condition of the digit span were used for executive functioning [30,31]. Language and executive functioning were tested by category fluency (animals) [32]. Missing data ranged from $n=19$ (3\%) (digit span forward) to $n=67$ (11\%) (RAVLT, delayed recall).

\section{MRI}

Subjects were scanned as part of clinical workup using a standardized protocol on a 1.0-, 1.5-, or 3.0-T system. All scans were visually rated by trained raters and subsequently evaluated in a consensus meeting with an experienced neuroradiologist [23]. Visual rating of medial temporal lobe atrophy (MTA) was performed using coronal T1-weighted images on a 5point (0-4) scale from the average score of the left and right sides [33]. Global cortical atrophy (GCA) was assessed visually on axial fluid-attenuated inversion recovery (FLAIR) images (range of scores 0-3) [34]. Parietal atrophy was rated using T1-weighted and FLAIR weighted images viewed in sagittal, axial, and coronal planes by computing an average score of the left and right sides (range 0-3) [35]. WMH were rated on axial FLAIR images using a four-step scale (range 0-3) [36]. Lacunes were defined as deep lesions $(3-15 \mathrm{~mm})$ with CSF-like signals on all sequences and were dichotomized as present or absent. Microbleeds were defined as small, round foci of hypointense signal up to $10 \mathrm{~mm}$ in brain parenchyma on T2*-weighted gradient echo images. The total number of microbleeds was counted and divided into three categories: zero, one or two, and three or more microbleeds. MRI data were available for 485 (79\%) subjects. 


\section{CSF}

CSF analyses were performed at the Neurochemistry Laboratory at the Department of Clinical Chemistry of the VUmc. CSF was obtained by lumbar puncture between the L3-L4 or L4-L5 intervertebral space by using a 25-gauge needle and collected into polypropylene tubes. Within $2 \mathrm{~h}$, the CSF was centrifuged at $1800 \times g$ for 10 minutes at $4{ }^{\circ} \mathrm{C}$, transferred to new polypropylene tubes, and stored at $-20{ }^{\circ} \mathrm{C}$ until biomarker analysis (within 2 months). $\beta$-Amyloid 1-42 (A $\left.\beta_{42}\right)$, tau, and tau phosphorylated at threonine $181(\mathrm{p}$-tau) were measured with commercially available enzyme-linked immunosorbent assays (Innotest; Fujirebio, Ghent, Belgium) [37]. CSF data were available for $466(76 \%)$ subjects.

\section{APOE genotyping}

DNA was isolated from $10 \mathrm{ml}$ of ethylenediaminetetraacetic acid blood. Apolipoprotein E ( $A P O E$ ) genotype was determined using the LightCycler APOE mutation detection method (Roche Diagnostics GmbH, Mannheim, Germany). According to APOE $\varepsilon 4$ allele status, patients were dichotomized into carriers (hetero- and homozygous) and noncarriers. $A P O E$ status was available for $562(91 \%)$ subjects.

\section{Outcome measure}

For each patient, we obtained information on all-cause mortality (died yes/no with a date of death) from the Dutch municipal population register. This register was searched on 19 October 2016. Causes of death cannot be determined from this municipal registry. We defined follow-up duration as the time between the date of baseline $\mathrm{AD}$ diagnosis and the date of death or, if alive, between the date of baseline $\mathrm{AD}$ diagnosis and 19 October 2016.

\section{Statistical analyses}

Statistical analyses were performed using IBM SPSS Statistics version 22 software (IBM, Armonk, NY, USA). $p<0.05$ was considered significant. Baseline characteristics were compared using parametric and nonparametric tests when appropriate. We used pattern analysis to explore the amount and randomness of missing data. Because missing data were at random, but not completely at random, we imputed all missing data imputed using multiple imputation, in which the missing values were estimated on the basis of other available baseline variables in 15 imputation cycles.

To allow comparison of results on different tests within patients, all continuous variables were standardized to z-scores. All neuropsychological tests, except TMT-A and TMT-B, as well as CSF A $\beta_{42}$, were inverted by computing $-1 \times \mathrm{z}$-score, with the result being that a higher score implied more advanced disease. We used Cox proportional hazards models to assess associations between all baseline determinants and mortality, taking into account time to death, using the pooled results of the 15 imputations. Each measure was assessed unadjusted (model 1), adjusted for age and sex (model 2), and adjusted additionally for MMSE and duration of

Table 1 Baseline characteristics of patients with Alzheimer's disease according to outcome

\begin{tabular}{|c|c|c|c|c|}
\hline & No. of patients & Alive $(n=403)$ & Died $(n=213)$ & $p$ Value \\
\hline \multicolumn{5}{|l|}{ Demographics } \\
\hline Female sex, $n(\%)$ & 616 & $218(54)$ & $91(43)$ & 0.007 \\
\hline Age, years & 616 & $66 \pm 7$ & $69 \pm 9$ & 0.000 \\
\hline APOE $\varepsilon 4$ carrier, $n(\%)$ & 562 & $250(67)$ & $119(63)$ & 0.280 \\
\hline Years of education & 616 & $11 \pm 3$ & $11 \pm 3$ & 0.675 \\
\hline Years of complaints & 611 & $3.2 \pm 2.6$ & $2.8 \pm 2.0$ & 0.066 \\
\hline Years to outcome & 616 & $5.3 \pm 1.8$ & $4.3 \pm 2.1$ & 0.000 \\
\hline Activities of daily living (DAD) & 372 & $83 \pm 17$ & $82 \pm 17$ & 0.450 \\
\hline \multicolumn{5}{|l|}{ Medical history } \\
\hline Smoking, $n(\%)$ & 599 & $185(47)$ & $98(49)$ & 0.640 \\
\hline Hypertension, n (\%) & 616 & $127(32)$ & $77(36)$ & 0.245 \\
\hline Hypercholesterolemia, n (\%) & 616 & $103(26)$ & $46(22)$ & 0.275 \\
\hline Diabetes mellitus, n (\%) & 616 & $31(8)$ & $15(7)$ & 0.770 \\
\hline Cardiovascular disease, $n$ (\%) & 616 & $71(18)$ & $53(25)$ & 0.032 \\
\hline No. of medications & 616 & $2.0 \pm 2.0$ & $2.4 \pm 2.1$ & 0.062 \\
\hline
\end{tabular}

Abbreviations: APOE Apolipoprotein E, DAD Disability Assessment for Dementia (range 0-100)

Years to outcome: in case of alive, follow-up duration; in case of died, duration to death

Data are presented as mean \pm SD unless otherwise specified. Group differences were calculated using Student's $t$ test for continuous variables. For categorical variables, the chi-square test was used 
complaints as a proxy of disease severity (model 3). Effect modification, using interaction terms for each variable with *age and "sex, was not found. Subsequently, we aimed to select the optimal combination of determinants by constructing a multivariate model using forward selection. The model was built by assessing all variables and consecutively selecting the variable with the lowest $p$ value in a stepwise manner until $p$ was $<$ 0.10 . In case of several variables with the same lowest $p$ value, we calculated the Wald statistics and selected the variable with the highest Wald value. Variables were added only when the overall model improved, as evaluated using the $-2 \log$-likelihood ratio. In an additional set of analyses, we performed similar analyses based on nonimputed data, and the results were comparable (see Additional file 1: Table S1 and S2). Finally, we created Kaplan-Meier curves for each of the variables selected by forward selection. Because all variables except for sex were continuous values, we used tertiles for the survival curves. Data are represented as HRs with accompanying 95\% CIs.

\section{Results}

Table 1 presents the baseline characteristics of the patients. After a follow-up of $4.9 \pm 2.0$ years, 213(35\%) patients had died (duration baseline AD diagnosis to death $4.3 \pm 2.1$ years) and $403(65 \%)$ patients were alive (follow-up duration $5.3 \pm 1.8$ years) on the $19^{\text {th }}$ October 2016. Patients who had died were more often male, older and more often had cardiovascular disease. There was no difference in self-reported duration of complaints or years or activities of daily living (as measured with the DAD.

Patients who had died performed worse at baseline on TMT-A and RAVLT immediate recall, but MMSE scores and performance on the other cognitive tests were similar. In addition, these patients' biomarkers were indicative of more severe AD pathology, with a higher MTA and GCA, lower $A \beta_{42}$, and higher p-tau values (Table 2).

We used Cox proportional hazards models to evaluate associations between the individual determinants and mortality, taking into account time to death (Tables 3 and 4). Male sex and older age were associated with an increased risk of mortality. After adjustment for age and sex, worse performance on MMSE, digit span backward, VAT naming, TMT-A, TMT-B, and RAVLT immediate recall and category fluency were associated with an increased risk of mortality. In addition, more severe MTA and GCA seen on MRI scans were associated with an increased risk of mortality. Duration of complaints, activities of daily living (as measured with the DAD), years of education, $A P O E$ \&4 presence, comorbidity, MRI measures of small vessel disease, and CSF biomarkers were not associated with mortality. When we adjusted
Table 2 Disease-specific characteristics at baseline, according to outcome

\begin{tabular}{|c|c|c|c|c|}
\hline & $\begin{array}{l}\text { No. of } \\
\text { patients }\end{array}$ & $\begin{array}{l}\text { Alive } \\
(n=403)\end{array}$ & $\begin{array}{l}\text { Died } \\
(n=213)\end{array}$ & $p$ Value \\
\hline \multicolumn{5}{|l|}{ Cognitive tests } \\
\hline MMSE & 616 & $22 \pm 3$ & $22 \pm 3$ & 0.480 \\
\hline Digit span forward & 597 & $11 \pm 3$ & $11 \pm 3$ & 0.908 \\
\hline Digit span backward & 593 & $7 \pm 3$ & $6 \pm 2$ & 0.154 \\
\hline VAT naming & 576 & $11 \pm 1$ & $11 \pm 2$ & 0.194 \\
\hline VAT memory & 579 & $6 \pm 4$ & $6 \pm 4$ & 0.641 \\
\hline TMT-A, seconds & 581 & $81 \pm 62$ & $92 \pm 64$ & 0.046 \\
\hline TMT-B, seconds & 581 & $299 \pm 235$ & $329 \pm 215$ & 0.079 \\
\hline RAVLT, immediate recall & 551 & $23 \pm 7$ & $22 \pm 8$ & 0.026 \\
\hline RAVLT, delayed recall & 549 & $2 \pm 2$ & $2 \pm 2$ & 0.391 \\
\hline Category fluency & 563 & $13 \pm 5$ & $13 \pm 6$ & 0.325 \\
\hline \multicolumn{5}{|l|}{ MRI } \\
\hline MTA & 484 & $1.2 \pm 0.8$ & $1.6 \pm 0.9$ & 0.000 \\
\hline PA & 470 & $1.2 \pm 0.8$ & $1.3 \pm 0.8$ & 0.185 \\
\hline GCA & 482 & $1.0 \pm 0.6$ & $1.2 \pm 0.7$ & 0.004 \\
\hline WMH & 485 & $1.0 \pm 0.8$ & $1.1 \pm 0.9$ & 0.152 \\
\hline Lacunes present, $n(\%)$ & 483 & $20(6)$ & $16(9)$ & 0.262 \\
\hline $\begin{array}{l}\text { Microbleeds by category, } \\
n(\%)\end{array}$ & 393 & & & 0.064 \\
\hline 0 microbleeds & & $181(75)$ & $112(74)$ & \\
\hline 1-2 microbleeds & & $41(17)$ & $17(11)$ & \\
\hline$\geq 3$ microbleeds & & $20(8)$ & $22(15)$ & \\
\hline Infarcts present, n (\%) & 482 & $3(1)$ & $4(2)$ & 0.257 \\
\hline \multicolumn{5}{|l|}{ CSF } \\
\hline $\mathrm{A} \beta_{42}, \mathrm{pg} / \mathrm{ml}$ & 466 & $525 \pm 172$ & $490 \pm 173$ & 0.037 \\
\hline $\mathrm{tau}, \mathrm{pg} / \mathrm{ml}$ & 460 & $662 \pm 340$ & $695 \pm 434$ & 0.374 \\
\hline $\mathrm{p}$-tau, pg/ml & 463 & $83 \pm 33$ & $91 \pm 45$ & 0.031 \\
\hline
\end{tabular}

Abbreviations: MMSE Mini Mental State Examination (score range 0-30), Digit span forward and backward (range 0-21), VAT Visual Association Test (naming range $0-12$, memory range $0-12$ ), TMT Trail Making Test (no range), RAVLT Rey Auditory Verbal Learning Task (immediate recall range $0-60$, delayed recall range 0-15), MTA Medial temporal lobe atrophy (range 0-4; average score of left and right sides), PA Parietal atrophy (range $0-3$; average score of left and right sides), GCA Global cortical atrophy (range 0-3), WMH White matter hyperintensities (range $0-3$ ), $A \beta_{42} \beta$-Amyloid 1-42, $p$-tau Tau phosphorylated at threonine 181, MRI Magnetic resonance imaging, CSF Cerebrospinal fluid Data are presented as mean \pm SD unless otherwise specified. Group differences were calculated using Student's $t$ test for continuous variables. For categorical variables, the chi-square test was used

additionally for MMSE and duration of complaints as a proxy for disease severity, all related variables from model 2, except MTA, remained associated with mortality.

Next, we aimed to identify the optimal combination of determinants in a multivariate model. With use of forward selection, the model included age (HR 1.31, 95\% CI $1.12-1.54, p=0.001$ ), male sex (HR 1.67, 95\% CI 1.26-2.21, $p=0.000$ ), digit span backward (HR 1.22, 
Table 3 Cox proportional hazards models used to evaluate influence of baseline characteristics and medical history on survival

\begin{tabular}{|c|c|c|c|c|c|c|}
\hline & \multicolumn{2}{|c|}{ Model 1 unadjusted } & \multicolumn{2}{|c|}{$\begin{array}{l}\text { Model } 2 \text { adjusted for age } \\
\text { and sex }\end{array}$} & \multicolumn{2}{|c|}{$\begin{array}{l}\text { Model 3: model } 2 \text { plus MMSE } \\
\text { and duration of complaints }\end{array}$} \\
\hline & $\mathrm{HR}(95 \% \mathrm{Cl})$ & $p$ value & $\mathrm{HR}(95 \% \mathrm{Cl})$ & $p$ Value & $\mathrm{HR}(95 \% \mathrm{Cl})$ & $p$ Value \\
\hline \multicolumn{7}{|l|}{ Demographics } \\
\hline Male sex ${ }^{a}$ & $1.57(1.20-2.07)$ & 0.001 & $1.60(1.22-2.11)$ & 0.001 & $1.79(1.35-2.37)$ & 0.000 \\
\hline Age & $1.27(1.11-1.46)$ & 0.001 & $1.29(1.12-1.48)$ & 0.000 & $1.33(1.15-1.53)$ & 0.000 \\
\hline Years of education & $0.99(0.86-1.13)$ & 0.844 & $0.97(0.84-1.11)$ & 0.636 & $1.0(0.90-11.9)$ & 0.671 \\
\hline Years of complaints & $0.88(0.76-1.03)$ & 0.107 & $0.88(0.76-1.03)$ & 0.103 & $0.87(0.74-1.01)$ & 0.060 \\
\hline APOE $\varepsilon 4$ carrier $^{\mathrm{a}}$ & $0.79(0.59-1.06)$ & 0.114 & $0.81(0.61-1.09)$ & 0.163 & $0.81(0.60-1.09)$ & 0.170 \\
\hline Activities of daily living (DAD) ${ }^{\mathrm{b}}$ & $1.13(0.97-1.31)$ & 0.124 & $1.11(0.95-1.29)$ & 0.204 & $1.09(0.94-1.26)$ & 0.278 \\
\hline \multicolumn{7}{|l|}{ Medical history } \\
\hline Smoking present ${ }^{a}$ & $1.18(0.89-1.55)$ & 0.250 & $1.09(0.82-1.45)$ & 0.541 & $1.12(0.85-1.49)$ & 0.419 \\
\hline Hypertension present ${ }^{a}$ & $1.24(0.94-1.64)$ & 0.130 & $1.11(0.83-1.49)$ & 0.467 & $1.10(0.82-1.47)$ & 0.528 \\
\hline Hypercholesterolemia present ${ }^{a}$ & $0.86(0.62-1.19)$ & 0.861 & $0.73(0.52-1.01)$ & 0.059 & $0.75(0.54-1.05)$ & 0.091 \\
\hline Diabetes mellitus present ${ }^{a}$ & $0.72(0.43-1.22)$ & 0.228 & $0.62(0.37-1.06)$ & 0.079 & $0.65(0.40-1.05)$ & 0.108 \\
\hline Cardiovascular disease present ${ }^{\mathrm{a}}$ & $1.35(0.99-1.84)$ & 0.060 & $1.07(0.77-1.48)$ & 0.700 & $1.09(0.78-1.51)$ & 0.625 \\
\hline No. of medications & $1.17(1.03-1.33)$ & 0.017 & $1.08(0.95-1.24)$ & 0.251 & $1.11(0.97-1.28)$ & 0.125 \\
\hline
\end{tabular}

Abbreviations: APOE Apolipoprotein E, DAD Disability Assessment for Dementia, MMSE Mini Mental State Examination

Data are presented as $\mathrm{HR}(95 \% \mathrm{Cl})$ using pooled data of 15 imputations per SD increase for continuous variables or for the presence of the dichotomous variable for mortality

a Dichotomous variable

${ }^{b}$ Because a lower score indicates worse performance, these scores were inverted

95\% CI 1.03-1.43, $p=0.018)$, TMT-A (HR 1.22, 95\% CI $1.06-1.41, p=0.005)$, MTA (HR 1.18, 95\% CI $1.01-1.38, p=0.038$ ), and CSF p-tau (HR 1.15, 95\% CI 1.00-1.32, $p=0.058)$. Survival curves for these variables are shown in Fig. 1. Of note, because $<50 \%$ of our subjects had died, median survival time can only be estimated from these curves.

\section{Discussion}

Our main finding is that despite their relatively young age, roughly one of three patients with AD had died with a mean of 5 years after diagnosis. Predisposing factors for an increased risk of mortality were older age, male sex, more severe executive dysfunction, presence of MTA, and higher p-tau in CSF, indicative of more severe AD pathology. By contrast, duration of complaints, level of activities of daily living, $A P O E \varepsilon 4$ status, and comorbidity were not related to mortality.

In our relatively young population (average age $67 \pm 8$ years) derived from a tertiary memory clinic cohort with mild to moderate dementia (all with MMSE scores > 16; average MMSE score 22), 35\% of the patients had died within 5 years after receiving their baseline diagnosis. This mortality rate is considerably higher than that of the general Dutch population [19]. Previous studies described slightly higher mortality rates, but most studies included patients older than 75 years of age or with severe dementia with MMSE scores < 20 [38-40]. Only a few studies have been focused on mortality in young patients with AD or less affected patients, showing comparable mortality rates [38, 41-43]. Extending these former studies, we evaluated not only comorbidity but also focused on disease-specific markers as determinants of mortality.

In addition to male sex and older age, both of which are known determinants of mortality in $\mathrm{AD}$ and in the general population, we found executive dysfunction, MTA, and higher p-tau in CSF, all reflecting more severe disease, to be determinants of mortality. Self-reported duration of complaints was not associated with mortality, indicating that the patients who died had more aggressive rather than more advanced disease. In line with this notion, there was hardly any difference at baseline in the severity of cognitive impairment between those who died within the study period and those who remained alive. Previous studies focused on neuropsychology have shown mainly an association with mortality when assessing decline over time but not at baseline [5, $38,39]$. In our study, we consistently found tests in the executive domain and, to a lesser degree, memory as determinants of mortality. A potential explanation for this finding is that subjects with executive dysfunction are at greater risk of dependency, increasing the risk of complications. Also, the executive domain seems to be a mediator for other cognitive domains, whereas tests for delayed recall were already at floor level in many patients [44]. This latter finding could explain why tests for delayed recall showed no association with survival. 
Table 4 Cox proportional hazards models used to evaluate influence of cognitive performance, magnetic resonance imaging, and cerebrospinal fluid at baseline on survival

\begin{tabular}{|c|c|c|c|c|c|c|}
\hline & \multicolumn{2}{|c|}{ Model 1 unadjusted } & \multicolumn{2}{|c|}{$\begin{array}{l}\text { Model } 2 \text { adjusted for age } \\
\text { and sex }\end{array}$} & \multicolumn{2}{|c|}{$\begin{array}{l}\text { Model 3: model } 2 \text { plus MMSE } \\
\text { and duration of complaints }\end{array}$} \\
\hline & HR $(95 \% \mathrm{Cl})$ & $p$ Value & $\mathrm{HR}(95 \% \mathrm{Cl})$ & $p$ Value & HR $(95 \% \mathrm{Cl})$ & $p$ Value \\
\hline \multicolumn{7}{|l|}{ Cognitive tests } \\
\hline $\mathrm{MMSE}^{\mathrm{a}}$ & $1.11(0.97-1.28)$ & 0.131 & $1.23(1.07-1.42)$ & 0.005 & $1.25(1.08-1.44)$ & 0.003 \\
\hline Digit span forward ${ }^{a}$ & $1.07(0.93-1.23)$ & 0.362 & $1.10(0.95-1.26)$ & 0.207 & $1.03(0.89-1.20)$ & 0.651 \\
\hline Digit span backward ${ }^{\mathrm{a}}$ & $1.21(1.05-1.40)$ & 0.008 & $1.31(1.13-1.52)$ & 0.000 & $1.24(1.06-1.46)$ & 0.009 \\
\hline VAT naming $^{a}$ & $1.15(1.01-1.31)$ & 0.037 & $1.14(1.01-1.30)$ & 0.042 & $1.11(0.97-1.27)$ & 0.136 \\
\hline VAT memory ${ }^{a}$ & $1.01(0.88-1.15)$ & 0.937 & $1.07(0.93-1.23)$ & 0.360 & $1.02(0.88-1.19)$ & 0.790 \\
\hline TMT-A & $1.21(1.07-1.37)$ & 0.003 & $1.29(1.14-1.47)$ & 0.000 & $1.23(1.08-1.41)$ & 0.003 \\
\hline TMT-B & $1.19(1.05-1.35)$ & 0.006 & $1.28(1.13-1.45)$ & 0.000 & $1.21(1.06-1.40)$ & 0.005 \\
\hline RAVLT, immediate recall ${ }^{a}$ & $1.23(1.06-1.43)$ & 0.008 & $1.19(1.02-1.38)$ & 0.025 & $1.11(0.95-1.30)$ & 0.193 \\
\hline RAVLT, delayed recall ${ }^{\mathrm{a}}$ & $0.96(0.84-1.10)$ & 0.533 & $0.96(0.83-1.10)$ & 0.507 & $0.90(0.78-1.04)$ & 0.154 \\
\hline Category fluency ${ }^{a}$ & $1.17(1.02-1.37)$ & 0.045 & $1.17(1.01-1.36)$ & 0.041 & $1.10(0.94-1.29)$ & 0.243 \\
\hline \multicolumn{7}{|l|}{ MRI } \\
\hline MTA & $1.26(1.10-1.44)$ & 0.001 & $1.18(1.02-1.37)$ & 0.030 & $1.15(0.98-1.34)$ & 0.081 \\
\hline PA & $1.12(0.97-1.30)$ & 0.113 & $1.10(0.95-1.28)$ & 0.192 & $1.12(0.96-1.29)$ & 0.143 \\
\hline GCA & $1.21(1.05-1.40)$ & 0.008 & $1.18(1.01-1.37)$ & 0.037 & $1.17(1.00-1.36)$ & 0.044 \\
\hline WMH & $1.16(1.01-1.33)$ & 0.041 & $1.07(0.92-1.25)$ & 0.364 & $1.05(0.90-1.22)$ & 0.518 \\
\hline Lacunes present ${ }^{\mathrm{b}}$ & $1.15(0.77-1.71)$ & 0.505 & $1.10(0.73-1.66)$ & 0.634 & $1.17(0.76-1.79)$ & 0.485 \\
\hline \multicolumn{7}{|l|}{ Microbleed categories } \\
\hline Microbleeds, 1-2 & $0.82(0.49-1.37)$ & 0.450 & $0.72(0.43-1.19)$ & 0.195 & $0.69(0.42-1.16)$ & 0.163 \\
\hline Microbleeds, $\geq 3$ & $1.09(0.80-1.47)$ & 0.598 & $1.03(0.76-1.40)$ & 0.840 & $1.01(0.74-1.37)$ & 0.956 \\
\hline Infarcts present ${ }^{b}$ & $1.11(0.63-2.00)$ & 0.710 & $1.15(0.64-2.05)$ & 0.641 & $1.11(0.60-2.05)$ & 0.727 \\
\hline \multicolumn{7}{|l|}{ CSF } \\
\hline $\mathrm{A} \beta_{42}^{\mathrm{a}}$ & $0.98(0.84-1.14)$ & 0.765 & $1.02(0.87-1.18)$ & 0.850 & $0.99(0.86-1.16)$ & 0.943 \\
\hline tau & $1.05(0.91-1.22)$ & 0.504 & $1.09(0.94-1.27)$ & 0.275 & $1.07(0.92-1.26)$ & 0.369 \\
\hline p-tau & $1.06(0.92-1.23)$ & 0.426 & $1.09(0.94-1.26)$ & 0.242 & $1.08(0.93-1.26)$ & 0.316 \\
\hline
\end{tabular}

Abbreviations: MMSE Mini Mental State Examination, VAT Visual Association Test, TMT Trail Making Test, RAVLT Rey Auditory Verbal Learning Task, MRI Magnetic resonance imaging, MTA Medial temporal lobe atrophy, PA Parietal atrophy, GCA Global cortical atrophy, WMH White matter hyperintensities score 3, CSF Cerebrospinal fluid, $A \beta_{42} \beta$-Amyloid 1-42, $p$-tau Tau phosphorylated at threonine 181

Data are presented as HR $(95 \% \mathrm{Cl})$ using pooled data of 15 imputations per SD increase for continuous variables or for the presence of the dichotomous variable for mortality

${ }^{a}$ Because a lower score indicates worse performance, these scores were inverted

${ }^{b}$ Dichotomous variable

To our knowledge in only two other studies have researchers assessed associations of MRI atrophy markers with mortality, with findings that global atrophy, but not MTA, was associated with mortality in dementia [12, 18]. An association of MTA and mortality in AD was found in a study conducted with computed tomographic scans [45]. In our univariate models, we found more severe MTA and global atrophy associated with increased risk of death; in the multivariate forward selection model, GCA was not included. Atrophy is seen on MRI scans as a marker of downstream neuronal degeneration [25]. In this study, other markers of neurodegeneration, such as p-tau in CSF, were also included in our multivariate forward selection model, which confirms the results of the few studies addressing CSF and mortality in $\mathrm{AD}[16,18]$. The effect of WMH seems attributable largely to age, because the prognostic value disappeared in the adjusted models. This is different from what has been found before and could potentially be explained by the relatively young age of our sample [12].

In line with previous studies, male sex was associated with higher mortality in $\mathrm{AD}$ [3]. It has been suggested that women present earlier in their disease course owing to more easily noticed impairment in household tasks, and hence they have a longer survival time [3]. Also, women more often lived alone and were more frequently widowed, leading to impairment being noticed earlier. We did not find an association with level of activities of 


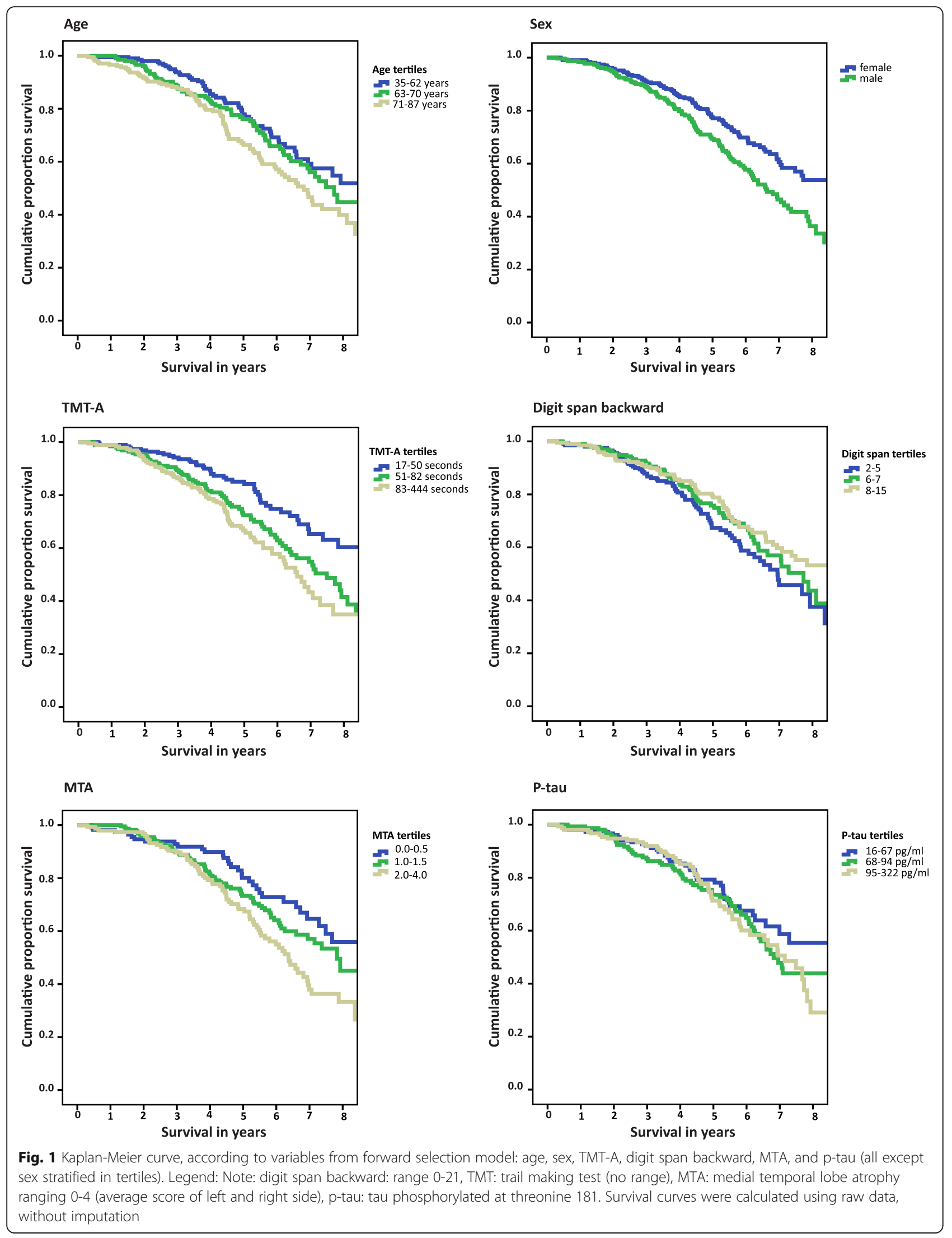


daily living (as measured by the DAD). We believe this is possibly most relevant in more advanced disease stages and not in our cohort, where activities of daily living were only mildly impaired in most patients $[41,46]$. Finally, and contrary to our expectations, we could not confirm smoking, comorbidity, or number of medications as predisposing factors for an increased risk of mortality. Previous studies have shown an association of cardiovascular risk factors with mortality, but these studies were focused mostly on older populations that are by definition at higher risk of both cardiovascular disease and mortality [11, 13-15, 46]. Also, a higher level of comorbidity has previously been shown to relate to survival time $[14,15]$, but again in older populations; in our present study, we used number of medications as a proxy of level of comorbidity and found no association [13]. Our study shows that the AD process itself, as reflected by neuropsychology as well as MRI and CSF biomarkers, has prognostic value in terms of mortality as well. This fits with the observation that patients with $\mathrm{AD}$ have higher rates of mortality than the general population and that $\mathrm{AD}$ is the swiftest growing cause of death in the Western world $[2,19]$.

Limitations of the present study are that our population was derived from a tertiary memory clinic, which hampers the generalizability of the results. However, the added value of our study is its focus on younger patients, for whom a paucity of data exists. We studied a broad range of determinants in patients with a relatively long followup duration. In addition, we included only patients with MMSE scores $\geq 16$ to prevent cognitive testing from being at floor level. Of note, even in our young, mild to moderately impaired cohort of patients with $\mathrm{AD}$, mortality was high. Another limitation might be the mean follow-up duration of $5.3 \pm 1.8$ years for the patients who remained alive, implying that these patients might have died shortly after this period. Nonetheless, all patients had a minimum follow-up of 2 years. Finally, we had information on medication use only at baseline and thus had no information on the prescription of cholinesterase inhibitors after the diagnosis AD. This could be a limitation because some studies have shown that cholinesterase inhibitors can increase survival, whereas others have shown no such effect or only in older patients [41, 43, 47]. Furthermore, we were not able to look at the relationship between use of antipsychotics and mortality [48, 49], because only a very small proportion of our subjects used these medications. However, use of antipsychotics is likely to occur later in the course of the disease. Among the strengths of the present study is our harmonized diagnostic protocol according to which all patients were assessed, because all patients were selected from the same memory clinic and received the same diagnostic workup and similar treatment and management.

\section{Conclusions}

Our results have important clinical implications. We found that $\mathrm{AD}$-related factors, rather than comorbidity or duration of complaints, were associated with increased mortality in our relatively young cohort. This knowledge enables timely dialogue on prognosis, even in young patients who are otherwise healthy.

\section{Additional file}

Additional file 1: Table S1. Cox proportional hazard models using nonimputed data; influence of baseline characteristics and medical history on survival status. Table S2. Cox proportional hazard models based on nonimputed data; influence of CSF and MRI on survival status. (DOCX $26 \mathrm{~kb}$ )

\section{Abbreviations}

$A \beta_{42}$ : $\beta$-Amyloid 1-42; AD: Alzheimer's disease; APOE: Apolipoprotein E; CSF: Cerebrospinal fluid; DAD: Disability Assessment for Dementia; FLAIR: Fluid-attenuated inversion recovery; GCA: Global cortical atrophy; MMSE: Mini Mental State Examination; MRI: Magnetic resonance imaging; MTA: Medial temporal lobe atrophy; PA: Parietal atrophy; p-tau: Tau phosphorylated at threonine 181; RAVLT: Rey Auditory Verbal Learning Task; TMT-A: Trail Making Test A; TMT-B: Trail Making Test B; VAT: Visual Association Test; WMH: White matter hyperintensities

\section{Acknowledgements}

Research done at the VUmc Alzheimer Center is part of the neurodegeneration research program of Amsterdam Neuroscience. The VUmc Alzheimer Center is supported by Alzheimer Nederland and Stichting VUmc Fonds. The clinical database structure was developed with funding from Stichting Dioraphte. HFMRM is appointed on a grant from the European Union Seventh Framework Program project PredictND under grant agreement 611005.

Funding

Not applicable.

\section{Availability of data and materials}

The datasets used and/or analyzed during the present study are available from the corresponding author on reasonable request.

\section{Authors' contributions}

HFMRM drafted the manuscript and analyzed/interpreted data. HL revised the manuscript and analyzed/interpreted data. TK revised the manuscript and interpreted data. AWL revised the manuscript and interpreted data. CET revised the manuscript and interpreted data. FB revised the manuscript and interpreted data. PS revised the manuscript and interpreted data. MvG revised the manuscript and interpreted data. JL revised the manuscript and analyzed/interpreted data. WMvdF drafted the manuscript, analyzed/ interpreted data, and supervised the project. All authors read and approved the final manuscript.

\section{Ethics approval and consent to participate}

The study was approved by the local medical ethics committee. All patients provided written informed consent for their clinical data to be used for research purposes

\section{Consent for publication}

Not applicable.

\section{Competing interests}

CET is a member of the Innogenetics International Advisory Boards of Fujirebio/ Innogenetics and Roche. FB serves/has served on the advisory boards of BayerSchering Pharma, Sanofi-Aventis, Biogen-Idec, Teva Pharmaceutical Industries, Merck-Serono, Novartis, Roche, Synthon BV, Jansen Research, and Genzyme. FB has received funding from the Dutch MS Society and the European Union Seventh Framework Program (EU-FP7) and has been a speaker at symposia 
organized by the Serono Symposia Foundation and Medscape. PS has served as a consultant for Wyeth-Elan, Genentech, Danone, and Novartis and has received funding for travel from Pfizer, Elan, Janssen, and Danone Research. JL reports that Combinostics Oy owns the following intellectual property rights related to this paper: (1) J. Koikkalainen and J. Lotjonen. Method for inferring the state of a system. Publication number US 7840510 B2; application number PCT/ Fl2007/050277; (2) J. Lotjonen, J. Koikkalainen, and J. Mattila. State inference in a heterogeneous system. Application number PCT/FI2010/050545; FI20125177. JL is a shareholder in Combinostics Oy. WMvdF performs contract research for Boehringer Ingelheim. Research programs of WMvdF have been funded by ZonMw, the Netherlands Organization for Scientific Research (now), EU-FP7, Alzheimer Nederland, Cardiovascular Onderzoek Nederland, Stichting Dioraphte, Gieskes-Striibis Fonds, Boehringer Ingelheim, Piramal Neuroimaging, Roche BV, and Janssen Stellar. All funding is paid to WMvdF's institution. The other authors declare that they have no competing interests.

\section{Publisher's Note}

Springer Nature remains neutral with regard to jurisdictional claims in published maps and institutional affiliations.

\section{Author details \\ 'Alzheimer Center, Department of Neurology, VU University Medical Center, Amsterdam Neuroscience, P.O. Box 7057, 1007, MB, Amsterdam, The Netherlands. ${ }^{2} V T T$ Technical Research Center of Finland Ltd, Tampere, Finland. ${ }^{3}$ Department of Medical Psychology, VU University Medical Center, Amsterdam Neuroscience, Amsterdam, The Netherlands. ${ }^{4}$ Neurochemistry Lab and Biobank, Department of Clinical Chemistry, VU University Medical Center, Amsterdam Neuroscience, Amsterdam, The Netherlands. ${ }^{5}$ Department of Radiology and Nuclear Medicine, VU University Medical Center, Amsterdam Neuroscience, Amsterdam, The Netherlands. Institute of Neurology, UCL, London, UK. ${ }^{7}$ Institute of Healthcare Engineering, UCL, London, UK. ${ }^{8}$ Combinostics Ltd, Tampere, Finland. ${ }^{9}$ Department of Epidemiology and Biostatistics, VU University Medical Center, Amsterdam Neuroscience, Amsterdam, The Netherlands.}

\section{Received: 9 November 2017 Accepted: 22 January 2018}

\section{Published online: 20 February 2018}

\section{References}

1. World Health Organization. Dementia fact sheet (No. 362). http://www.who. int/mediacentre/factsheets/fs362/en/. Accessed 11 Oct 2016.

2. Brodaty H, Seeher K, Gibson L. Dementia time to death: a systematic literature review on survival time and years of life lost in people with dementia. Int Psychogeriatr. 2012;24:1034-45.

3. Todd S, Barr S, Roberts M, Passmore AP. Survival in dementia and predictors of mortality: a review. Int J Geriatr Psychiatry. 2013;28:1109-24.

4. Wattmo C, Londos E, Minthon L. Risk factors that affect life expectancy in Alzheimer's disease: a 15-year follow-up. Dement Geriatr Cogn Disord. 2014; 38:286-99.

5. Leoutsakos JM, Forrester SN, Corcoran CD, Norton MC, Rabins PV, Steinberg MI, Tschanz JT, Lyketsos CG. Latent classes of course in Alzheimer's disease and predictors: the Cache County Dementia Progression Study. Int I Geriatr Psychiatry. 2015;30:824-32.

6. Rabins PV, Schwartz S, Black BS, Corcoran C, Fauth E, Mielke M, Christensen J, Lyketsos C, Tschanz J. Predictors of progression to severe Alzheimer's disease in an incidence sample. Alzheimers Dement. 2013;9:204-7.

7. Spalletta G, Long JD, Robinson RG, Trequattrini A, Pizzoli S, Caltagirone C, Orfei MD. Longitudinal neuropsychiatric predictors of death in Alzheimer's disease. J Alzheimers Dis. 2015;48:627-36.

8. Tschanz JT, Corcoran CD, Schwartz S, Treiber K, Green RC, Norton MC, Mielke MM, Piercy K, Steinberg M, Rabins PV, et al. Progression of cognitive, functional, and neuropsychiatric symptom domains in a population cohort with Alzheimer dementia: the Cache County Dementia Progression Study. Am J Geriatr Psychiatry. 2011;19:532-42.

9. van de Vorst IE, Koek HL, de Vries R, Bots ML, Reitsma JB, Vaartjes I. Effect of vascular risk factors and diseases on mortality in individuals with dementia: a systematic review and meta-analysis. J Am Geriatr Soc. 2016;64:37-46.

10. Koedam EL, Pijnenburg YA, Deeg DJ, Baak MM, van der Vlies AE, Scheltens $P$, van der Flier WM. Early-onset dementia is associated with higher mortality. Dement Geriatr Cogn Disord. 2008;26:147-52.
11. van de Vorst IE, Vaartjes I, Geerlings MI, Bots ML, Prognosis KHL. of patients with dementia: results from a prospective nationwide registry linkage study in the Netherlands. BMJ Open. 2015;5:e008897.

12. Henneman WJ, Sluimer JD, Cordonnier C, Baak MM, Scheltens $P$, Barkhof $F$, van der Flier WM. MRI biomarkers of vascular damage and atrophy predicting mortality in a memory clinic population. Stroke. 2009:40:492-8.

13. Garcia-Ptacek S, Farahmand B, Kareholt I, Religa D, Cuadrado ML, Eriksdotter M. Mortality risk after dementia diagnosis by dementia type and underlying factors: a cohort of 15,209 patients based on the Swedish Dementia Registry. J Alzheimers Dis. 2014;41:467-77.

14. Larson EB, Shadlen MF, Wang L, McCormick WC, Bowen JD, Teri L, Kukull WA. Survival after initial diagnosis of Alzheimer disease. Ann Intern Med. 2004;140:501-9.

15. Zekry D, Herrmann FR, Graf CE, Giannelli S, Michel JP, Gold G, High KKH. levels of comorbidity and disability cancel out the dementia effect in predictions of long-term mortality after discharge in the very old. Dement Geriatr Cogn Disord. 2011;32:103-10.

16. Degerman Gunnarsson M, Lannfelt L, Ingelsson M, Basun H, Kilander L. High tau levels in cerebrospinal fluid predict rapid decline and increased dementia mortality in Alzheimer's disease. Dement Geriatr Cogn Disord. 2014;37:196-206.

17. Wallin AK, Blennow K, Zetterberg H, Londos E, Minthon L, Hansson O. CSF biomarkers predict a more malignant outcome in Alzheimer disease. Neurology. 2010;74:1531-7.

18. Nagga $K$, Wattmo C, Zhang Y, Wahlund LO, Palmqvist S. Cerebral inflammation is an underlying mechanism of early death in Alzheimer's disease: a 13-year cause-specific multivariate mortality study. Alzheimers Res Ther. 2014;6:41.

19. Centraal Bureau voor de Statistiek. Statline [updated 2003]. https://opendata cbs.nl/statline/\#/CBS/nl/dataset/83795NED/table?ts=1517513589647. Accessed 3 Jan 2018.

20. van der Vlies AE, Koedam EL, Pijnenburg YA, Twisk JW, Scheltens P, van der Flier WM. Most rapid cognitive decline in APOE $\varepsilon 4$ negative Alzheimer's disease with early onset. Psychol Med. 2009;39:1907-11.

21. Ueki A, Shinjo H, Shimode H, Nakajima T, Morita Y. Factors associated with mortality in patients with early-onset Alzheimer's disease: a five-year longitudinal study. Int J Geriatr Psychiatry. 2001;16:810-5.

22. Palmqvist S, Hertze J, Minthon L, Wattmo C, Zetterberg H, Blennow K Londos E, Hansson O. Comparison of brief cognitive tests and CSF biomarkers in predicting Alzheimer's disease in mild cognitive impairment: six-year follow-up study. PLoS One. 2012;7:e38639.

23. van der Flier WM, Pijnenburg YA, Prins N, Lemstra AW, Bouwman FH, Teunissen CE, van Berckel BN, Stam CJ, Barkhof F, Visser PJ, et al. Optimizing patient care and research: the Amsterdam Dementia Cohort. J Alzheimers Dis. 2014;41:313-27.

24. Gelinas I, Gauthier L, McIntyre M, Gauthier S. Development of a functional measure for persons with Alzheimer's disease: the disability assessment for dementia. Am J Occup Ther. 1999;53:471-81.

25. McKhann GM, Knopman DS, Chertkow H, Hyman BT, Jack Jr CR, Kawas CH, Klunk WE, Koroshetz WJ, Manly JJ, Mayeux R, et al. The diagnosis of dementia due to Alzheimer's disease: recommendations from the National Institute on Aging-Alzheimer's Association workgroups on diagnostic guidelines for Alzheimer's disease. Alzheimers Dement. 2011;7:263-9.

26. McKhann G, Drachman D, Folstein M, Katzman R, Price D, Stadlan EM. Clinical diagnosis of Alzheimer's disease: report of the NINCDS-ADRDA Work Group under the auspices of Department of Health and Human Services Task Force on Alzheimer's Disease. Neurology. 1984;34:939-44.

27. Folstein MF, Folstein SE, McHugh PR. "Mini-mental state": a practical method for grading the cognitive state of patients for the clinician. J Psychiatr Res. 1975;12:189-98.

28. Lindeboom J, Schmand B, Tulner L, Walstra G, Jonker C. Visual Association. Test to detect early dementia of the Alzheimer type. J Neurol Neurosurg Psychiatry. 2002;73:126-33.

29. Schmand B, Houx P, de Koning I. Norms of psychological tests for usage in the clinical neuropsychology [in Dutch]. Utrecht, the Netherlands: Dutch Association of Psychologists; 2012. https://www.psynip.nl/sectorensecties/ sector-gezondheidszorg/neuropsychologie/. Accessed 11 Oct 2016.

30. Reitan R. Validity of the Trail Making Test as an indicator of organic brain damage. Percept Mot Skills. 1958;8:271-6.

31. Lindeboom J, Matto D. Digit series and Knox cubes as concentration tests for elderly subjects [in Dutch]. Tijdschr Gerontol Geriatr. 1994;25:63-8. 
32. Van der Elst W, Van Boxtel MP, Van Breukelen GJ, Jolles J. Normative data for the Animal, Profession and Letter M Naming verbal fluency tests for Dutch speaking participants and the effects of age, education, and sex. J Int Neuropsychol Soc. 2006:12:80-9.

33. Scheltens $P$, Launer $L$, Barkhof F, Weinstein HC, van Gool WA. Visual assessment of medial temporal lobe atrophy on magnetic resonance imaging: interobserver reliability. J Neurol. 1995;242:557-60.

34. Pasquier F, Leys D, Weerts JG, Mounier-Vehier F, Barkhof F, Scheltens P. Inter- and intraobserver reproducibility of cerebral atrophy assessment on MRI scans with hemispheric infarcts. Eur Neurol. 1996;36:268-72.

35. Koedam EL, Lehmann $M$, van der Flier WM, Scheltens P, Pijnenburg YA, Fox N, Barkhof F, Wattjes MP. Visual assessment of posterior atrophy development of a MRI rating scale. Eur Radiol. 2011;21:2618-25.

36. Fazekas F, Chawluk JB, Alavi A, Hurtig HI, Zimmerman RA. MR signal abnormalities at 1.5 T in Alzheimer's dementia and normal aging. AJR Am J Roentgenol. 1987;149:351-6.

37. Duits FH, Teunissen CE, Bouwman FH, Visser PJ, Mattsson $N$, Zetterberg $H$, Blennow K, Hansson O, Minthon L, Andreasen N, et al. The cerebrospinal fluid "Alzheimer profile": easily said, but what does it mean? Alzheimers Dement. 2014;10:713-23. e2

38. Hui JS, Wilson RS, Bennett DA, Bienias JL, Gilley DW, Evans DA. Rate of cognitive decline and mortality in Alzheimer's disease. Neurology. 2003;61: 1356-61.

39. Wilson RS, Li Y, Aggarwal NT, McCann JJ, Gilley DW, Bienias JL, Barnes LL, Evans DA. Cognitive decline and survival in Alzheimer's disease. Int J Geriatr Psychiatry. 2006;21:356-62.

40. Soto ME, Andrieu S, Cantet C, Reynish E, Ousset PJ, Arbus C, GilletteGuyonnet S, Nourhashemi F, Vellas B. Predictive value of rapid decline in Mini Mental State Examination in clinical practice for prognosis in Alzheimer's disease. Dement Geriatr Cogn Disord. 2008;26:109-16.

41. Wattmo C, Londos E, Minthon L. Longitudinal associations between survival in Alzheimer's disease and cholinesterase inhibitor use, progression, and community-based services. Dement Geriatr Cogn Disord. 2015;40:297-310.

42. Morris JC, Edland S, Clark C, Galasko D, Koss E, Mohs R, van Belle G, Fillenbaum G, Heyman A. The Consortium to Establish a Registry for Alzheimer's Disease (CERAD): Part IV. Rates of cognitive change in the longitudinal assessment of probable Alzheimer's disease. Neurology. 1993; 43:2457-65.

43. Gillette-Guyonnet S, Andrieu S, Nourhashemi F, Gardette V, Coley N, Cantet C, Gauthier S, Ousset PJ, Vellas B. Long-term progression of Alzheimer's disease in patients under antidementia drugs. Alzheimers Dement. 2011;7: 579-92.

44. Pillai JA, Bonner-Jackson A, Walker E, Mourany L, Cummings JL. Higher working memory predicts slower functional decline in autopsy-confirmed Alzheimer's disease. Dement Geriatr Cogn Disord. 2014;38:224-33.

45. Claus JJ, van Gool WA, Teunisse S, Walstra GJ, Kwa VI, Hijdra A, Verbeeten Jr B, Koelman JH, Bour $L$, Ongerboer De Visser BW. Predicting survival in patients with early Alzheimer's disease. Dement Geriatr Cogn Disord. 1998;9: 284-93

46. Rountree SD, Chan W, Pavlik VN, Darby EJ, Doody RS. Factors that influence survival in a probable Alzheimer disease cohort. Alzheimers Res Ther. 2012;4:16.

47. Nordstrom P, Religa D, Wimo A, Winblad B, Eriksdotter M. The use of cholinesterase inhibitors and the risk of myocardial infarction and death: a nationwide cohort study in subjects with Alzheimer's disease. Eur Heart J. 2013;34:2585-91.

48. Scarmeas N, Brandt J, Albert M, Hadjigeorgiou G, Papadimitriou A, Dubois B, Sarazin M, Devanand D, Honig L, Marder K, et al. Delusions and hallucinations are associated with worse outcome in Alzheimer disease. Arch Neurol. 2005;62:1601-8.

49. Nielsen RE, Lolk A, Valentin JB, Andersen K. Cumulative dosages of antipsychotic drugs are associated with increased mortality rate in patients with Alzheimer's dementia. Acta Psychiatr Scand. 2016;134:314-20.

\section{Submit your next manuscript to BioMed Central and we will help you at every step:}

- We accept pre-submission inquiries

- Our selector tool helps you to find the most relevant journal

- We provide round the clock customer support

- Convenient online submission

- Thorough peer review

- Inclusion in PubMed and all major indexing services

- Maximum visibility for your research

Submit your manuscript at www.biomedcentral.com/submit
Biomed Central 